\title{
O problema da representação política em Maquiavel
}

\author{
Felipe Charbel Teixeira
}

ADVERSE, Helton. Maquiavel: politica e retórica. Belo Horizonte: Editora UFMG, 2009.

Este não é mais um livro sobre Maquiavel. Mais um livro tratando da modernidade do escritor florentino e das "grandes inovaçôes" do seu pensamento, como a separação entre ética e política. Mais um livro sobre o Maquiavel fundador da ciência política moderna, da Razão de Estado, da abordagem sociológica da religião. Mais um livro que lida com a obra maquiaveliana na chave das oposiçôes binárias: pensador republicano ou conselheiro de príncipes, homem de letras ou secretário da República. Mais um livro a apontar a contribuição intelectual do autor à "grande cadeia do ser": ruptura com o pensamento escolástico, com o humanismo cívico e retórico, com as doutrinas morais cristãs ou com a filosofia política clássica como um todo.

Maquiavel: política e retórica, originalmente uma tese de doutoramento em Filosofia, é um estudo que exige do leitor - ao menos do leitor não-familiarizado com as pesquisas mais recentes sobre Maquiavel -, uma disponibilidade toda especial. É preciso abandonar as visões pré-formadas, os lugares-comuns enraizados nos manuais de ciência política, renunciar à sombra do maquiavelismo, para compreender os caminhos da hermenêutica de Helton Adverse, as sutilezas de sua argumentação, a recusa de atalhos, posições apressadas ou soluções simples. Um livro complexo sobre uma obra complexa, que faz jus a Maquiavel ao não reduzir a interpretação de seus textos a meros axiomas. Ao mesmo tempo, trata-se de um livro marcado pela aporia resultante do tratamento da política e da retórica como metacódigos descolados da ética.

O ponto de partida de Adverse, professor de Filosofia da UFMG, não é exatamente inovador: trata-se, antes de tudo, de trazer a retórica (de volta) ao centro da filosofia política. Eclipsada na modernidade iluminista, deslegitimada como arte do engodo, da persuasão a qualquer preço, tida como principal inimiga do racionalismo científico a que a análise política deveria se submeter, a retórica retorna ao palco principal da filosofia em meados do século XX, na esteira da chamada "virada linguística”. Um dos resultados visíveis dessa tendência é o crescimento contínuo, nos meios acadêmicos, do interesse pela produção letrada prémoderna, especialmente do Renascimento, que tem se revelado um campo riquíssimo para filósofos e historiadores. Nas últimas três décadas os estudos maquiavelianos não estiveram indiferentes a essa orientação.

Que significa tomar como objeto de pesquisa a retórica em Maquiavel? Uma primeira possibilidade diz respeito à análise dos escritos do secretário florentino à luz das convençôes, preceitos, medidas dispositivas e elocutivas presentes em tratados antigos ou humanistas de arte retórica. Isso vem sendo feito com alguma sistematicidade por poucos, porém importantes, autores, como Victoria Kahn, Virginia Cox, Maurizio Viroli e Eugene Garver. O segundo caminho envolve o exame das implicações profundas, e, por que não dizer, radicais, da presença maciça desses códigos nos escritos de Maquiavel, ou seja, a retórica como aspecto incontornável de sua produção discursiva, como veículo para o exercício do seu engenho e elemento organizador de sua visão de mundo.

Um autor, contudo, não pode ser facilmente desvinculado das tradições interpretativas a que se encontra ligado, especialmente após quatro séculos de "trabalho da obra". Isso obriga o estudioso da obra de Maquiavel a se defrontar criticamente com visões há muito enraizadas entre filósofos e cientistas políticos acerca do seu suposto lugar cativo na "história do pensamento político". Um desdobramento possível (talvez o mais relevante) desse deslocamento hermenêutico na direção do estudo do caráter constitutivo da retórica nos escritos maquiavelianos é a desnaturalização de interpretaçôes calcificadas. Como pensar, por exemplo, um Maquiavel fundador da moderna ciência da 
política à luz das inúmeras tópicas retóricas recorrentes em seus textos, argumentos-tipo sem autoria? Como conciliar a defesa da "verdade efetiva das coisas" do capítulo XV de O Príncipe com a peroração em estilo grave que encerra o opúsculo? Como estabelecer um ponto de convergência entre os fins "honestos" dos Discorsi e os ensinamentos imorais e/ou amorais que preenchem o livro sobre os principados? A análise retórica, necessariamente intertextual, mesmo que não possa dar respostas definitivas a essas questões, transforma radicalmente a compreensão dos escritos maquiavelianos ao permitir que sejam pensados com base em novas chaves interpretativas, tomando por base o critério da verossimilhança normativa - o que tais textos podem ter significado em seus contextos originais de elocução?

Mas Adverse opta por não fazer uma leitura retórica da obra de Maquiavel, deixando em segundo plano o exame da construção discursiva e do poder performativo dos seus escritos. Nesse sentido, o livro não pode ser enquadrado nas possibilidades elencadas acima. A visada do autor se pretende mais filosófica que histórica, e diz respeito à compreensão do político como fenômeno, segundo a chave analítica proposta pelo filósofo francês Claude Lefort. O político é pensado aqui não em oposição à retórica, mas como um campo por ela impregnado; e Maquiavel é considerado o autor que explorou de maneira mais aguda, quase à exaustão - e não necessariamente por meio de reflexões teóricas -, as diversas possibilidades que se abrem no entrelaçamento entre retórica e política.

Uma dessas possibilidades, examinada com inteligência por Adverse, diz respeito à dimensão imagética da política. A produção da imagem é vista pelo autor como um dos aspectos centrais do discurso político de Maquiavel: "a ação política requer um saber e uma técnica para a formação de uma imagem favorável ao príncipe", saber e técnica que são retóricos. Não, porém, no sentido usual, e mais restrito, de persuasão - entendida como consequência direta, quase necessária, da lógica racional discursiva bem aplicada. Adverse enfatiza precisamente o tratamento maquiaveliano ao outro lado da eloquência: a retórica das paixões, o que justifica o excurso pela obra de Aristóteles, embora se saiba hoje (e o autor é o primeiro a reconhecer) que a formação de Maquiavel se deu predominantemente no contato com os autores latinos.

Esse deslocamento do racional para a retórica das paixôes é a precondição necessária à reinterpretação da categoria de "verdade efetiva", um dos pilares da tradição analítica que atribui a Maquiavel um caráter fundador, seja da Razão de Estado, da ciência política moderna ou do realismo político. Partindo da análise de Adverse, podemos depreender que a "verdade efetiva" não é uma verdade "por trás" dos fenômenos. Trata-se de uma verdade que só se apresenta como tal no horizonte dos efeitos produzidos pelo discurso, pela ação, pela aparência ou pelas três coisas ao mesmo tempo. Trata-se de uma verdade composta por verossímeis, uma verdade que joga com a opinião comum, com a doxa, sem se confundir com ela. Uma verdade composta não só de razão, mas também - e especialmente - de páthos e éthos. "O éthos do homem político", diz Adverse, "é concebido por Maquiavel como uma imagem capaz de atuar sobre os homens que vivem sob um regime político". O páthos, por sua vez, é a condição para que se produza uma presença imagética, para que a ação política consiga ser efetiva, no apelo às sensaçôes mais valorizadas em uma "cultura da visibilidade" como a existente na Florença renascentista: "as paixóes atuam sobre o juízo; em contrapartida, o juízo também pode afetar as paixões".

De acordo com Adverse, a retórica das paixões foi explorada a fundo por Maquiavel, que a trouxe para o centro do debate sobre a representação política. $\mathrm{O}$ discurso político maquiaveliano joga com os costumes aceitos, com a opinião comum, com significados socialmente arraigados - como reputação, glória, honestidade e liberalidade - para, partindo deles, produzir suas verdades efetivas: presenças que jamais se constituem de antemão, fora do horizonte das contingências históricas. Daí a existência, para o autor, de diversos "níveis retóricos no pensamento de Maquiavel", como "a retórica utilizada pelos personagens da história política”, "a retórica que deve ser colocada em ação pelo autor político" e "a retórica utilizada por Maquiavel na estrutura e no conteúdo de seus textos". A retórica está onde está o político, em suas múltiplas dimen- 
sões, e estas não se descolam de suas representações - por exemplo, o inganno e a aparência necessários à realização de grandes coisas.

Por sua estreita vinculação com a política, a retórica não pode ser considerada um instrumento neutro de persuasão, tampouco uma simples techné. Esse argumento, inteiramente adequado, é repetido exaustivamente por Adverse. Mas como articulá-lo à pressuposição da existência de "níveis retóricos" em Maquiavel? Como esses níveis podem ser hierarquizados? E se não são hierarquizáveis, como evitar uma visão instrumentalizante da retórica? Esta é multifacetada, mas não tem níveis: a coesão da instituição retórica, até o século XVII, baseava-se precisamente numa representação da estabilidade universal dos valores. Como conceber, então, a indissociabilidade entre retórica e política apenas margeando o debate ético? A "filosofia política vazada na linguagem da retórica” revela-se, na análise de Adverse, uma filosofia política esvaziada de sua dimensão ética - como se a retórica não refratasse visões de mundo, cosmologias, estruturas sociais, como se ela própria não conduzisse a uma hierarquia discursiva fundada em regras tácitas de conveniência, real alicerce de cada um dos textos compostos por Maquiavel. Não me parece convincente, nesse sentido, a hipótese defendida por Adverse, com base na pesquisa de Virginia Cox sobre a recepção do Ad Herennium no século XVI, de uma liberação da "retórica do "filtro moral" com que os humanistas até então a revestiam. Até mesmo porque, no horizonte dessa "liberação", só resta conceber a retórica como techné.

O ônus da recusa de uma análise retórica dos escritos de Maquiavel é a ocultação da hierarquia discursiva que ordena, como horizonte regulatório, suas reflexões. A ética, no livro de Adverse, é reduzida à análise do éthos, à imagem construída e mobilizada pelos atores políticos. Maquiavel é assim apresentado como uma espécie de meta-filósofo político, um filósofo que refletiu de maneira pormenorizada sobre as condiçóes diversas $\mathrm{da}$ representação política, entendida no sentido teatral de presentificação: "podemos dizer que em seu pensamento", diz Adverse, "a relação da representação com o objeto representado, o referente, é menos importante do que seu caráter efetivo, isto é, sua capacidade de produzir efeitos na realidade ou efeitos de realidade". Cabe perguntar, contudo, se estes efeitos de realidade podem ser tomados como fins em si, ou se eles são meios cujos fins somente a análise retórica de textos como $O$ Príncipe e os Discorsi pode revelar. Mas a formulação dessa pergunta equivale a cobrar do autor respostas que ele não se propõe a dar. O problema central do texto é exatamente o exame da natureza retórica da política, e no que se propõe a realizar Maquiavel: retórica e política é um livro instigante, de rara erudição, que sugere inúmeros caminhos aos seus leitores atentos, especialmente no que diz respeito às questóes da produção da imagem e da representação política. Uma importante contribuição não só aos estudos maquiavelianos, mas à filosofia política em geral. 